\title{
Is Timely and Appropriate Antifungal Drug Enough for Survival of Adult Cases with Candidaemia? Five-year Experience
}

\author{
MT Yildirmak, H Gedik, F Şimşek, NE Iris, A Gücüyener
}

\begin{abstract}
Objective: Candidaemia is the fourth most common cause of nosocomial bloodstream infections. The objective of this paper was to evaluate the risk factors associated with mortality in patients with candidaemia with respect to Candida species and their susceptibilities, retrospectively.

Methods: All consecutive patients who developed candidaemia at an 800-bed training and research hospital were enrolled in this retrospective, observational, single centre study during the period June 2006 to December 2011.

Results: A total of 97 candidaemia episodes were identified in 97 patients during the study period with an overall incidence of four episodes/10 000 admissions in adults. Crude 30-day mortality rates among patients with candidaemia were 56\% (55 of 97 cases). Urinary catheterization, immunosuppressive therapy, acute physiology and chronic health evaluation (APACHE) II score $(\geq 16)$ and hypoalbuminaemia were found to be independent risk factors for fatal candidaemia.

Conclusions: Adult cases with candidaemia who have risk factors associated with mortality are more likely to have poor prognosis despite appropriate and timely initiated antifungal drug treatment. Empiric antifungal drug should be tailored according to the severity of the patients' conditions and local antifungal susceptibility.
\end{abstract}

Keywords: Adult, antifungal drug, candidaemia, mortality, risk factors

\section{¿Es el Uso Oportuno y Adecuado de Antimicóticos Suficiente para la Supervivencia de Casos de Adultos con Candidemia? Cinco Años de Experiencia}

MT Yildirmak, H Gedik, F Şimşek, NE Iris, A Gücüyener

\begin{abstract}
RESUMEN
Objetivo: La candidemia es la cuarta causa más común de infecciones nosocomiales del flujo sanguíneo. El objetivo del presente trabajo fue evaluar los factores de riesgo asociados con la mortalidad en pacientes con candidemia con respecto a las especies de Candida y sus susceptibilidades, de manera retrospectiva.

Métodos: Todos los pacientes consecutivos que desarrollaron candidemia en un hospital de capacitación e investigación de 800 camas, fueron inscritos en este estudio retrospectivo, observacional, monocéntrico, durante el periodo de junio de 2006 a diciembre de 2011.

Resultados: Se identificaron un total de 97 episodios de candidemia en 97 pacientes durante el período de estudio con una incidencia general de cuatro episodios/10 000 ingresos en adultos. Las tasas brutas de mortalidad de 30 días entre los pacientes con candidemia fueron 56\% (55 de 97 casos). Se halló que la cateterización urinaria, la terapia inmunosupresiva, y la puntuación $(\geq 16)$ de la escala de Evaluación de la fisiología aguda y salud crónica (APACHE II) así como la hipoalbuminemia, constituyen factores de riesgo para una candidemia fatal.

Conclusiones: Los casos adultos con candidemia que tienen factores de riesgo asociados con mortalidad son más propensos a tener un pronóstico pobre a pesar del tratamiento apropiado y
\end{abstract}

From: Department of Infectious Diseases and Clinical Microbiology, Ministry of Health, Okmeydani Training and Research Hospital, Istanbul, Turkey.
Correspondence: Dr H Gedik, Department of Infectious Diseases and Clinical Microbiology, Ministry of Health, Okmeydani Training and Research Hospital, Istanbul, Turkey. E-mail: habipgedik@gmail.com 
oportuno con medicamentos antimicóticos. Los antimicóticos empírico se deben adaptar según la severidad de las condiciones de los pacientes y la susceptibilidad antifúngica local.

Palabras claves: Adulto, antimicóticos, candidemia, mortalidad, factores de riesgo

West Indian Med J 2013; 62 (8): 725

\section{INTRODUCTION}

Candida genus is a member of normal flora in the gastrointestinal tract and adult skin and the yeasts which contain approximately 200 species that are widespread in nature (1). Candidaemia is defined as growth of a Candida species in at least one blood culture with clinical findings (2). Candidaemia is the fourth most common cause of nosocomial bloodstream infections and comprise nine per cent of the cases in a national survey of hospitals in the United States of America (USA) from 1995 to $2002(3,4)$. The incidence of nosocomial candidaemia varies by intensive care unit (ICU), ward, hospital and countries. Costs increase $\$ 40000$ per episode of candidaemia $(5,6)$. Candida species, which cause candidaemia, vary in the studies; for instance, $46 \%$ of 2019 bloodstream isolates were reported as $C$ albicans in a multicentre surveillance between 2004 and 2008 in the USA (7). $C$ glabrata was reported to be responsible for $26 \%$ of all candidaemia cases, followed by $C$ parapsilosis $(16 \%), C$ tropicalis (8\%) and $C$ krusei [3\%] (7-9). Identification and susceptibility of isolated Candida species are crucial to initiate the appropriate antifungal drug that affects the prognosis, due to increasing primary and acquired resistance among Candida species $(2,10)$. Requirement of standardized antifungal susceptibility tests is clear, since timely and appropriate antifungal treatment and low fluconazole resistance rates were reported to be related to lower mortality rates (11, 12).

The aim of this study is to evaluate the risk factors associated with mortality in patients with candidaemia with respect to Candida species and their susceptibilities, retrospectively.

\section{SUBJECTS AND METHODS}

\section{Study design and data collection}

All consecutive patients who developed candidaemia at a training and research hospital that includes three ICUs (resuscitation, surgery, neurosurgery) and 800 beds with about 42000 admissions per year were enrolled in the study during the period June 2006 to December 2011. This study was approved by the institutional review ethics committee. In this retrospective observational study, the patients who had systemic inflammatory response (fever, hypothermia, leukocytosis or leukopenia, tachycardia, tachypnoea, hypotension) with at least one blood culture that yielded any Candida species were included in the study. Patients who had insufficient information or contamination regarding blood culture that yielded any Candida species were excluded from this study. The following data were extracted from the patient charts: age, gender, co-morbidities and risk factors in the preceding 30 days before the onset of candidaemia (recent surgery, central venous access devices (CVADs), neutropaenia, hyperalimentation, and administration of corticosteroids and antimicrobials or systemic antifungal agents. Acute physiology and chronic health evaluation (APACHE) II scores, laboratory findings, clinical signs of sepsis, results of diagnostic studies, antifungal treatment and outcome were collected. The number of admissions to hospital in a year was acquired from the hospital administration. Empiric antifungal drug was initiated if a patient had persistent fever with risk factors for fungal infection and was under antibiotic treatment or if a blood culture of a patient who had clinical signs and symptoms in accordance with infection yielded yeasts, pending identification and susceptibility testing. Antifungal drug was changed depending on identified Candida species and antifungal susceptibility.

\section{Definitions}

Adults who were older than 14 years old were included in the study. Relapse was defined as yielding a positive blood culture within 30 days of the first positive blood culture after clinical and microbiological response. Central-line associated candidaemia was defined as peripheral blood culture taken at least two hours before catheter culture that yielded the same Candida species which grew up in catheter culture or removed catheter tip culture $(\geq 15 \mathrm{CFU}$ on the plates which tip was rolled on it). Neutropaenia was defined as an absolute neutrophil count (ANC) of $<1.0 \times 10^{9} / \mathrm{L}$ and impaired renal function was a serum creatinine $>0.17$ $\mathrm{mmol} / \mathrm{L}$. Sepsis and severe sepsis were defined according to international definitions (13). Immunosuppressive therapy was defined as cytotoxic therapy or total body irradiation within three months before the onset of candidaemia or systemic cortisone ( $\geq 40 \mathrm{mg}$ per day at the start of cortisone treatment) within one month before the onset of candidaemia. The antifungal drug was initiated on the day of or after the date when the blood culture that yielded positive for any Candida species was drawn. Overall mortality was defined as all death within 30 days after diagnosis. If $\mathrm{C}$-reactive protein (CRP) was $8 \mathrm{mg} / \mathrm{dL}$ or more, it was considered as elevated. If aspartate aminotransferase (AST) and alanine aminotransferase (ALT) were $40 \mathrm{IU} / \mathrm{L}$ and more, they were considered as elevated. Hypoxia was defined as oxygen saturation less than $90 \%$ or arterial oxygen pressure less than $60 \mathrm{mmHg}$. Diarrhoea was defined as three or more watery 
stools in a day. Anaemia was defined as haemoglobin levels below $13 \mathrm{~g} / \mathrm{dL}$ in men and below $12 \mathrm{~g} / \mathrm{dL}$ in women by World Health Organization criteria. Thrombocytopaenia was defined as a platelet count $\leq 150 \times 10^{9}$ L. Leukocytosis was defined as any value above $10 \times 10^{9} \mathrm{~L}$. Leukopenia was defined as any value under 4 x $10^{9}$ L. Hypoalbuminaemia was defined as a serum albumin level less than $3.5 \mathrm{~g} / \mathrm{dL}$. The incidence of candidaemia was calculated as the ratio of the total number of patients per 10000 admissions.

\section{Microbiological methods}

In total, 16943 blood samples inoculated aseptically into bottles of the BacT/Alert 3D automated colorimetric system (bioMerieux, Marcy l'Etoile, France) were incubated for seven days within the study time. Isolated yeasts from blood cultures were identified by morphologic examination on Sabouraud Dextrose Agar (Oxoid, Istanbul, Turkey) plate, germ-tube formation and API ID 32C (bioMerieux, France) at the species level. ATB Fungus 2 microdilution kit was used (biomerieux, Lyon, France) for susceptibility testing according to the CLSI (formerly NCCLS) broth microdilution M27A2 protocol as follows: for amphotericin B, 5-flucytocine, fluconazole, itraconazole and voriconazole (14). Resistance was defined as minimum inhibitory concentration (MIC) $\geq$ $64 \mathrm{mg} / \mathrm{L}$ (and susceptible dose-dependent (S-DD) as an MIC of $16-32 \mathrm{mg} / \mathrm{L}$ ) for fluconazole, MIC $\geq 1 \mathrm{mg} / \mathrm{L}$ for itraconazole and $\mathrm{MIC} \geq 4 \mathrm{mg} / \mathrm{L}$ for voriconazole, $\mathrm{MIC}>0.5$ $\mathrm{mg} / \mathrm{L}$ for amphotericin $\mathrm{B}$ and $\mathrm{MIC}>0.5 \mathrm{mg} / \mathrm{L}$ for flucytosine. C parapsilosis ATCC 22019 and C krusei ATCC 6258 were used as quality control strains. Repetitive strains, which were isolated from the same materials of the same patients, and isolates which were unidentified at the species level, were excluded. C krusei was defined as resistant to fluconazole due to intrinsic resistance.

\section{Statistical analysis}

Data were analysed using SPSS 13.0 (Chicago, IL, USA). Continuous variables were described as mean \pm standard deviation and range. Percentile values were described without decimal. To evaluate factors associated with mortality, univariate analyses were performed using the Pearson $\chi^{2}$ test, or Fisher's exact test for categorical variables and unpaired Student's $t$-test for continuous variables. Bivariate logistic regression analysis was conducted to obtain unadjusted odds ratios and revealed as (odds ratio (OR), 95\% confidence interval, $p$-value) candidaemia in comparison of both survivor and non-survivor groups. Risk factors that reached statistical significance $(p<0.05)$ using a forward selection process remained in the model. All tests were based on two-tailed tests and $p$-values $<0.05$ were considered as significant.

\section{RESULTS}

A total of 97 candidaemia episodes were identified in 97 patients with an overall incidence of 4.19 episodes/10 000 admissions in adults during the study period. From 2006 to 2011 , incident density rates were calculated as $2.38(\mathrm{n}=5)$, $3.57(\mathrm{n}=15), 5(\mathrm{n}=21), 5.47(\mathrm{n}=23), 4.04(\mathrm{n}=17)$ and 3.8 $(\mathrm{n}=16)$ per 10000 admissions in each year, respectively. Of 97 patients, 51 cases were male, mean age was $50.51 \pm 21.12$ years, range of ages was between 15 and 90 years. Candida isolates of ICU patients composed $76 \%(n=74 / 97)$ of all isolates (C parapsilosis $(\mathrm{n}=24 / 39,63 \%), C$ albicans $(\mathrm{n}=$ $21 / 32,21 \%)$ and $C$ tropicalis $(\mathrm{n}=13 / 19,68 \%)$ and others) followed by the haematology ward $(\mathrm{n}=12,12 \%)$ and surgery ward $(n=9,9 \%)$. Underlying conditions were recorded in 62 (63\%) patients, and surgery was the most common co-morbid factor, as recorded in 55 cases (56\%). Mean APACHE II scores of the patients $(n=74)$ were $12.73 \pm 6.24$. Centralline catheter $(n=82,84 \%)$ and urinary catheter $(n=81,83 \%)$ were the most common risk factors in the cases. Hypoxia (n $=49)$ and sepsis $(n=36)$ were the most common clinical findings in the cases. C-reactive protein (CRP) elevation ( $\mathrm{n}$ $=94)$ and hypoalbuminaemia $(\mathrm{n}=90)$ were the most common laboratory findings in the patients (Tables 2, 3). Concurrent bacteraemia developed with methicillin resistant $S$ aureus (MRSA) in 11 cases and methicillin resistant coagulase negative staphylococci (MR-CNS) in 10 cases, $P$ aeruginosa in three cases, $E$ coli in two cases, and $A$ baumannii, and $S$ marcescens in one case each. Candida strains were also isolated from urine cultures $(n=27)$, and catheter cultures $(n=9)$. Central-line associated candidaemia developed with $C$ parapsilosis in five cases and $C$ albicans in four cases. Peritoneal fluid cultures yielded $C$ albicans in three cases, $C$ parapsilosis in two cases and $C$ tropicalis in one case (Table 1). Fluconazole was initiated as empirical antifungal drug in $20(62 \%)$ cases with $C$ albicans, $26(68 \%)$ cases with $C$ parapsilosis and eight cases (42\%) with $C$

Table 1: Candida species and their antifungal susceptibilities of the patients with candidaemia $(n=97)$

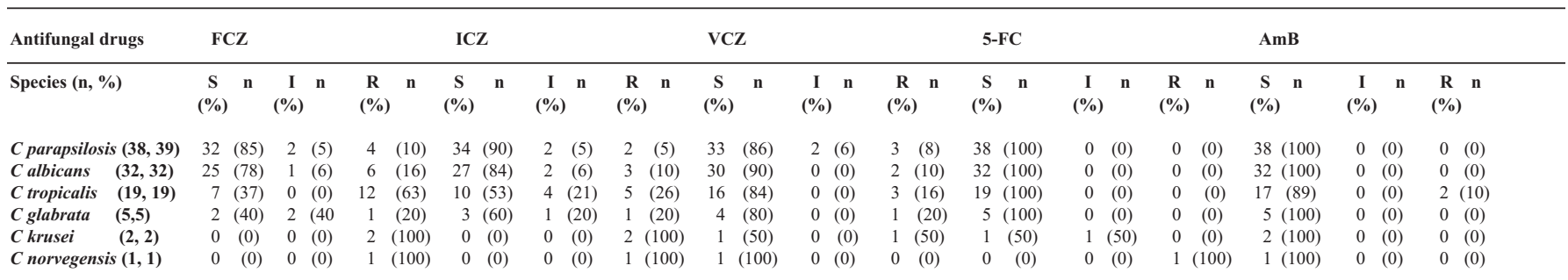

FCZ: fluconazole, ICZ: itraconazole, VCZ: voriconazole, 5-FC: 5-flucytosine, AmB: amphotericin B, S: susceptible, I: intermediate, R: resistant 
tropicalis. Amphotericin B (AmB) was initiated as empirical antifungal drug in seven (21\%) cases with $C$ albicans, four (10\%) cases with $C$ parapsilosis and three cases (15\%) with $C$ tropicalis. Caspofungin (CAS) was initiated as empirical antifungal drug in five (15\%) cases with $C$ albicans, eight
(21\%) cases with $C$ parapsilosis, and six cases (31\%) with $C$ tropicalis. Urinary catheterization $(\mathrm{OR}=0.28 ; 95 \% \mathrm{CI}: 0.08$, $0.88 ; p=0.03)$, immunosuppressive therapy $(\mathrm{OR}=0.29$; 95\% CI: $0.09,0.92 ; p=0.039)$, APACHE II score $(\geq 16)[\mathrm{OR}$ $=0.3 ; 95 \%$ CI: $0.12,0.75 ; p=0.008]$ and hypoalbuminaemia

Table 2: Distribution of categorized variables by survival group in the patients with candidaemia $(n=97)$

\begin{tabular}{|c|c|c|c|c|c|}
\hline & Total (n, \%) & $\begin{array}{c}\text { Survivor }(\mathrm{n}=42) \\
\text { n }(\%)\end{array}$ & $\begin{array}{c}\text { Non-survivor }(n=55) \\
n(\%)\end{array}$ & Odds ratio (\% 95 CI) & $p$ \\
\hline Age (years) & $50.51 \pm 21.124$ & $49.13 \pm 18.64$ & $51.01 \pm 19.43$ & & 0.87 \\
\hline Male/female & $49 / 48$ & $22 / 20$ & $27 / 28$ & & 0.748 \\
\hline \multicolumn{6}{|l|}{ Interventions } \\
\hline Central venous catheter & $(82,84)$ & $37(88)$ & $45(81)$ & & 0.572 \\
\hline Urinary catheter & $(81,83)$ & $31(73)$ & $50(90)$ & $0.28(0.08,0.88)$ & 0.03 \\
\hline Total parenteral nutrition & $(52,53)$ & $19(45)$ & $33(60)$ & & 0.158 \\
\hline Surgery & $(60,61)$ & $23(54)$ & $37(71)$ & & 0.292 \\
\hline Transfusion & $(53,54)$ & $23(54)$ & $30(54)$ & & 0.983 \\
\hline Mechanic ventilation & $(67,69)$ & $26(61)$ & $41(74)$ & & 0.183 \\
\hline Broad-spectrum antibiotic use & $(75,77)$ & $30(71)$ & $45(81)$ & & 0.228 \\
\hline \multicolumn{6}{|l|}{ Underlying conditions } \\
\hline Co-morbid conditions & $(74,76)$ & $31(73)$ & $43(78)$ & & 0.638 \\
\hline Immunosuppression therapy & $(19,19)$ & $5(11)$ & $14(25)$ & $0.29(0.09,0.92)$ & 0.039 \\
\hline Neutropaenia & $(18,18)$ & $10(23)$ & $8(14)$ & & 0.247 \\
\hline Diabetes mellitus & $(17,17)$ & $6(14)$ & $11(20)$ & & 0.460 \\
\hline Malignancy & $(31,31)$ & $17(40)$ & $14(25)$ & & 0.117 \\
\hline Haematological disorders & $(15,15)$ & $6(14)$ & $9(16)$ & & 0.779 \\
\hline Respiratory tract diseases & $(16,16)$ & $10(23)$ & $6(10)$ & & 0.091 \\
\hline \multicolumn{6}{|l|}{ Clinical findings } \\
\hline APACHE II score $(\geq 16)$ & $(35,47)$ & $9(12)$ & $26(35)$ & $0.3(0.12,0.75)$ & 0.008 \\
\hline Gastrointestinal bleeding & $(12,12)$ & 8 (19) & $4(7)$ & & 0.545 \\
\hline Hypoxia & $(49,50)$ & $17(40)$ & $32(58)$ & & 0.103 \\
\hline Septic shock $(n=16)$ & $(16,16)$ & $6(14)$ & $10(18)$ & & 0.607 \\
\hline Mucositis & $(17,17)$ & $10(23)$ & $7(12)$ & & 0.331 \\
\hline Diarrhoea & $(12,12)$ & 8 (19) & $4(7)$ & & 0.119 \\
\hline
\end{tabular}

APACHE $=$ acute physiology and chronic health evaluation

Table 3: Laboratory and microbiological findings by survival group in the patients with candidaemia $(\mathrm{n}=97)$

\begin{tabular}{|c|c|c|c|c|c|}
\hline & Total (n, \%) & $\begin{array}{c}\text { Survivor } \\
(\mathrm{n}=42) \\
\mathrm{n}(\%)\end{array}$ & $\begin{array}{l}\text { Non-survivor } \\
\quad(\mathbf{n}=\mathbf{5 5}) \\
\text { n }(\%)\end{array}$ & Odds ratio (\%95 CI) & $p$ \\
\hline \multicolumn{6}{|l|}{ Laboratory findings } \\
\hline CRP elevation & $(83,85)$ & $38(90)$ & $45(81)$ & & 0.26 \\
\hline Anaemia & $(68,70)$ & $26(61)$ & $42(76)$ & & 0.124 \\
\hline Hypoalbuminaemia & $(65,67)$ & $21(50)$ & $44(80)$ & $4(1.63,9.79)$ & 0.002 \\
\hline Decreased creatinine clearance & $(18,18)$ & $7(16)$ & $11(20)$ & & 0.675 \\
\hline Thrombocytopaenia & $(27,27)$ & $13(31)$ & $14(25)$ & & 0.55 \\
\hline ALT elevation & $(25,25)$ & $11(26)$ & $14(25)$ & & 0.935 \\
\hline AST elevation & $(40,41)$ & $18(42)$ & $22(40)$ & & 0.777 \\
\hline \multicolumn{6}{|l|}{ Microbiological findings } \\
\hline Concurrent bacteraemia & $(28,28)$ & $11(26)$ & $17(30)$ & & 0.61 \\
\hline Candida growth in urine culture & $(27,27)$ & $11(26)$ & $16(29)$ & & 0.752 \\
\hline Candida growth in catheter culture & $(9,9)$ & $3(7)$ & $6(10)$ & & 0.728 \\
\hline Candida growth in peritoneal fluid & $(6,6)$ & $3(7)$ & $3(5)$ & & 0.733 \\
\hline Growth of $C$ albicans species & $(32,32)$ & $13(31)$ & $19(34)$ & & 0.419 \\
\hline Growth of non- $C$ albicans species & $(65,67)$ & $31(73)$ & $34(61)$ & & 0.21 \\
\hline Fluconazole resistance & $(14,14)$ & $5(11)$ & $9(16)$ & & 0.533 \\
\hline Fluconazole treatment & $(50,51)$ & $20(47)$ & $30(54)$ & & 0.499 \\
\hline
\end{tabular}

CRP: C-reactive protein, AST: aspartate aminotransferase, ALT: alanine aminotransferase, CI: Confidence interval 
$(\mathrm{OR}=4 ; 95 \%$ CI: $1.63,9.79 ; p=0.002)$ were found to be independent risk factors for fatal candidaemia (Tables 2, 3). Crude 30-day mortality rates among patients with candidaemia were $56 \%$ (55 of 97 cases). Blood culture controls drawn 72 hours after antifungal treatment were negative in 45 patients of 55 fatal cases and all surviving patients. Caspofungin was initiated empirically in 18 of 42 survivor cases and 15 of 55 fatal cases $(p=0.109)$. Amphotericin B was initiated empirically in four of 42 survivor cases and 10 of 55 fatal cases $(p=0.26)$. Fluconazole was changed to CAS after 72 hours in nine survivor patients and nine non-survivor patients. Switching to either CAS or voriconazole did not achieve clinical response in two haematological patients who were under AmB or CAS treatment.

\section{DISCUSSION}

Candida bloodstream infections (CBI) are the fourth most common cause overall of haematogenous infections in the USA and they were reported as fourth to seventh in Europe $(5,15)$. Incidence of candidaemia in adult patients increased until 2009 and then decreased in each year at our hospital. The overall incidence of nosocomial candidaemia at our hospital - 4.19 cases per 10000 hospital admissions - is higher than two of density figures which have been reported as $1.68,5.6$ and 0.58 per 10000 hospital admissions in two university hospitals and one training and research hospital in Turkey, respectively (16-18). The incidence of bloodstream fungal infections was reported from 0.28 to 0.96 per 1000 admissions in the USA and from 0.2 to 0.38 in Europe, whereas these rates varied between 1.2 and $5.3(0.2-0.5$ cases per 1000 patient-days) in Latin America $(5,19,20)$. Almost all studies from different countries and Turkey described increasing incidence density rates of CBIs with non-albican species as found in our study $(17,18,21,24)$. A few studies from Turkey, USA and Asia reported that non-albican species predominated among other species in candidaemia attacks as $C$ parapsilosis predominated in our study, whereas other studies from Turkey and Europe revealed in favour of $C$ albicans $(8,16,17,21,24)$. Widespread azole use, fungal ecology of hospitals and countries cause diversity of species which cause candidaemia. C parapsilosis candidaemia was found to be related to vascular catheters and parenteral nutrition (25). $C$ tropicalis was reported to be related to cancer and neutropaenia (28). C krusei and C glabrata fungaemias were reported to be associated with previous exposure to azoles (28). Most of these cases of candidaemia were from ICU and haematology wards as reported in other studies $(29,30)$. Patients who are followed-up at those wards are more likely to have candidaemia due to immune compression, broad spectrum antibiotic use, colonization of several body sites, disruption of physiological barriers in the digestive tract and other factors $(29,30)$. Colonization rates were reported between five and 15 per cent in patients who were admitted to ICU, but those rates progressively increase to $50-80 \%$ as a result of prolonged exposure to many risk factors, such as major surgery, parenteral nutrition, dialysis and antibiotics (31-33). However, only 5-30\% of colonized patients will develop candidaemia, which is usually a lateonset ICU infection $(34,35)$. Wey and colleagues reported that patients receiving more than three antimicrobial drugs have 12.5 times higher risk for candidaemia (36). Central venous catheter, urinary catheter, co-morbid conditions, total parenteral nutrition, surgery, transfusion, mechanic ventilation and broad-spectrum antibiotic use were described to be risk factors that predisposed to candidaemia, as in our study $(20,22,36)$.

Fluconazole sensitivity of $C$ parapsilosis and $C$ albicans isolates that comprised $73 \%$ of all Candida isolates indicates that fluconazole could be initiated for patients who have uncomplicated sepsis and normal renal and hepatic function and no history of azole exposure in ICU and other wards. Fluconazole resistance rates have been reported from 0.3 to $10 \%$ in different studies (37-41). But higher voriconazole resistance rates have been reported in $C$ tropicalis isolates from patients with cancer or neutropaenia. Physicians should take into consideration development of candidaemia under voriconazole treatment due to increasing selection of voriconazole-resistant Candida species (26). Amphotericin B or ecinocandins should be chosen for patients who have history of azole exposure in case of development of $C$ krusei and $C$ glabrata fungaemias that have higher azole resistance rates, as in our study $(42,43)$. Itraconazole resistance rates in our study highlight azole resistance status in Turkey, as the study by Kiraz and Öz reported that only seven $C$ krusei isolates were resistant to AmB, whereas $80 \%(\mathrm{n}=1653), 76 \%(\mathrm{n}=1572)$ and $99 \%$ $(\mathrm{n}=2061)$ of all candida isolates were susceptible to fluconazole, itraconazole and amphotericin B, respectively (44).

As crude-30 day mortality rates were reported from $20 \%$ to $63 \%$, rates of our study $(56 \%)$ were similar to other studies from Turkey [56\% and 58\%] $(16,17,20,45)$. Delayed or inappropriate antifungal treatment decreases survival rates $(12,46,47)$. Antifungal drug was initiated as soon as possible after identification of yeasts and their susceptibilities in our study. Attributed mortality was reported between $15 \%$ and $25 \%$ in adults $(6,7)$. Mean age (50 years) in our study was older than those reported in previous studies $(48,49)$. Urinary catheter, immunosuppression therapy, hypoalbuminaemia and APACHE II score $(\geq 16)$ were determined to be risk factors associated with mortality in our study. Staying in ICU, mechanical ventilation, total parenteral nutrition, urinary catheterization, malignancy, any surgical procedures and central venous catheterization, no response to antifungal treatment, underlying disease other than trauma, high Charlson index, poor renal function and shock were described as mortality related risk factors in patients with candidaemia $(17,28,50)$. Concurrent bacteraemia and fluconazole resistance were not determined to increase mortality rates in our study as the study of 
Jutiamornlerd et al reported (50). Although previous studies recommended the removal of the catheter after identifying the candidaemia, Nucci and colleagues reported that catheter removal by 24 or 48 hours after treatment initiation had no effect on overall treatment response, mortality and mycological eradication in an analysis of 842 patients $(6,51,52)$. Removing the catheter should be evaluated against the patient's benefits and harms. Severity of illness and underlying conditions of the patients are more likely to affect treatment response rates and prognosis. Ecinocandins, amphotericin B and voriconazole should be chosen if patients are haemodynamically unstable, or have CVADs, previous azole exposure or azole prophylaxis. Treatment should be continued at least two weeks following the last positive culture (6).

\section{CONCLUSION}

Adult cases with candidaemia and who have risk factors associated with mortality are more likely to have poor prognosis despite appropriate and timely initiated antifungal drug treatment. Empirical choice of antifungal drug should be tailored with respect to the severity of patients and local antifungal susceptibility.

\section{ACKNOWLEDGEMENT}

We certify that there is no conflict of interest with any financial organization regarding the subject discussed in the manuscript. We appreciate the recommendations of Dr Onur Karatuna about our study.

\section{REFERENCES}

1. Hazen KC, Howell SA. Candida, Cryptococcus, and other yeasts of medical importance. In: Murray PR, Baron EJ, Jorgensen JH, Landry ML, Pfaller MA, eds. Manual of clinical microbiology. $9^{\text {th }}$ ed. Washington DC: ASM Press; 2007:1762-88.

2. Bennet JE. Candida species. In: Mandell GL, Bennet JE, Dolin R, eds. Principles and practice of infectious diseases. $7^{\text {th }}$ ed. Philadelphia: Churchill Livingstone; 2010: 3225-40.

3. Wisplinghoff H, Bischoff T, Tallent SM, Seifert H, Wenzel RP, Edmond MB. Nosocomial bloodstream infections in US hospitals: analysis of 24,179 cases from a prospective nationwide surveillance study. Clin Infect Dis 2004; 39: 309-17.

4. Pfaller MA, Diekema DJ. Epidemiology of invasive candidiasis: a persistent public health problem. Clin Microbiol Rev 2007; 20: 133-63.

5. Pappas PG, Kauffman CA. Clinical practice guidelines for the management of candidiasis: 2009 update by the Infectious Diseases Society of America. Clin Infect Dis 2009; 48: 503-35.

6. Morgan J, Meltzer MI, Plikaytis BD, Sofair AN, Huie-White S, Wilcox $\mathrm{S}$ et al. Excess mortality, hospital stay, and cost due to candidaemia : a case-control study using data from population-based candidaemia surveillance. Infect Control Hosp Epidemiol 2005; 26: 540-7.

7. Horn DL, Neofytos D, Anaissie EJ, Fishman JA, Steinbach WJ, Olyaei AJ et al. Epidemiology and outcomes of candidemia in 2019 patients: data from the prospective antifungal therapy alliance registry. Clin Infect Dis 2009; 48: 1695 .

8. Messer SA, Jones RN, Fritsche TR. International surveillance of Candida spp. and Aspergillus spp.: report from the SENTRY Antimicrobial Surveillance Program (2003). J Clin Microbiol 2006; 44: 1782.

9. Trofa D, Gácser A, Nosanchuk JD. Candida parapsilosis, an emerging fungal pathogen. Clin Microbiol Rev 2008; 21: 606.
10. Beck-Sague C, Jarvis WR. Secular trends in the epidemiology of nosocomial fungal infections in the United States, 1980-1990. National Nosocomial Infections Surveillance system. J Infect Dis 1993; 167: 1247-51.

11. Garey KW, Rege M, Pai MP, Mingo DE, Suda KJ, Turpin RS et al. Time to initiation of fluconazole therapy impacts mortality in patients with candidemia: a multi-institutional study. Clin Infect Dis 2006; 43: 25-31.

12. Baddley JW, Patel M, Bhavnani SM, Moser SA, Andes DR. Association of fluconazole pharmacodynamics with mortality in patients with candidemia. Antimicrob Agents Chemother 2008; 52: 3022-8.

13. American College of Chest Physicians/Society of Critical Care Medicine Consensus Conference: definitions for sepsis and organ failure and guidelines for the use of innovative therapies in sepsis. Crit Care Med 1992; 20: 864-74.

14. National Committee for Clinical Laboratory Standards. Reference method for broth dilution antifungal susceptibility testing of yeasts second edition. Approved Standard M27-A2. Wayne, PA, USA: NCCLS; 2002.

15. Sifuentes-Osornio J, Corzo-León DE, Ponce-de-León LA. Epidemiology of invasive fungal infections in Latin America. Curr Fungal Infect Rep 2012; 6: 23-34.

16. Yenigün BK, Kuloğlu F, Doğan ÇA, Akata F. Evaluation of epidemiological characteristics and risk factors of candidemia in adult patients in a tertiary-care hospital. Mikrobiyol Bul 2011; 45: 489-503.

17. Erdem I, Oguzoglu N, Ozturk DE, Ozgultekin A, Sengoz IA, Ceran N et al. Incidence, etiology and risk factors associated with mortality of nosocomial candidemia in a tertiary care hospital in Istanbul, Turkey. Med Princ Pract 2010; 19: 463-7.

18. Yapar N, Uysal U, Yucesoy M, Cakir N, Yuce A. Nosocomial bloodstream infections associated with Candida species in a Turkish University Hospital. Mycoses 2006; 49: 134-8.

19. Nucci M, Queiroz-Telles F, Tobón AM, Restrepo A, Colombo AL. Epidemiology of opportunistic fungal infections in Latin America. Clin Infect Dis 2010; 51: 561-70.

20. Colombo AL, Guimaraes T, Silva LR, de Almeida Monfardini LP, Cunha AK, Rady P et al. Prospective observational study of candidemia in Sao Paulo, Brazil: incidence rate, epidemiology and predictors of mortality. Infect Control Hosp Epidemiol 2007; 28: 5706.

21. Chakrabarti A, Mohan B, Shrivastava SK, Marak RS, Ghosh A, Ray P. Change in distribution \& antifungal susceptibility of Candida species isolated from candidaemia cases in a tertiary care centre during 1996-2000. Indian J Med Res 2002; 116: 5-12.

22. Fridkin SK, Jarvis WR. Epidemiology of nosocomial fungal infections. Clin Microbiol Rev 1996; 9: 499-511.

23. Metwally L, Walker MJ, Coyle PV, Hay RJ, Hedderwick S, McCloskey BV et al. Trends in candidemia and antifungal susceptibility in a university hospital in Northern Ireland 2001-2006. J Infect 2007; 55: $174-8$.

24. Arendrup MC, Fuursted K, Gahrn-Hansen B, Jensen IM, Knudsen JD, Lundgren B et al. Seminational surveillance of fungemia in Denmark: notably high rates of isolates with reduced azole susceptibility. J Clin Microbiol 2005; 43: 4434-40.

25. Clark TA, Slavinski SA, Morgan J, Lott T, Arthington-Skaggs BA, Webb RM et al. Epidemiologic and molecular characterization of an outbreak of Candida parapsilosis bloodstream infections in a community hospital. J Clin Microbiol 2004; 42: 4468-72.

26. Imhof A, Balajee SA, Fredricks DN, Englund JA, Marr KA. Breakthrough fungal infections in stem cell transplant recipients receiving voriconazole. Clin Infect Dis 2004; 39: 743-6.

27. Lin MY, Carmeli Y, Zumsteg J, Flores EL, Tolentino J, Sreeramoju P et al. Prior antimicrobial therapy and risk for hospital acquired Candida glabrata and Candida krusei fungemia: a case-case-control study. Antimicrob Agents Chemother 2005; 49: 4555-60.

28. Bassetti M, Ansaldi F, Nicolini L, Malfatto E, Molinari MP, Mussap M et al. Incidence of candidaemia and relationship with fluconazole use in an intensive care unit. J Antimicrob Chemother 2009; 64: 625-9. 
29. Vincent JL, Anaissie E, Bruining H, Demajo W, el-Ebiary M, Haber J et al. Epidemiology, diagnosis and treatment of systemic Candida infection in surgical patients under intensive care. Intensive Care Med 1998; 24: 206-16.

30. Kullberg BJ, Sobel JD, Ruhnke M, Pappas PG, Viscoli C, Rex JH et al. Voriconazole versus a regimen of amphotericin B followed by fluconazole for candidaemia in nonneutropenic patients: a randomised non-inferiority trial. Lancet 2005; 366: 1435-42.

31. Dupont H, Bourichon A, Paugam-Burtz C, Mantz J, Desmonts JM. Can yeast isolation in peritoneal fluid be predicted in intensive care unit patients with peritonitis? Crit Care Med 2003; 31: 752-7.

32. Eggimann P, Francioli P, Bille JR, Schneider R, Wu MM, Chapuis G et al. Fluconazole prophylaxis prevents intra-abdominal candidiasis in high risk surgical patients. Crit Care Med 1999; 27: 1066-72.

33. Sandven P, Qvist H, Skovlund E, Giercksky KE. Significance of Candida recovered from intraoperative specimens in patients with intraabdominal perforations. Crit Care Med 2002; 30: 541-7.

34. Leroy O, Gangneux JP, Montravers P, Mira JP, Gouin F, Sollet JP et al. Epidemiology, management, and risk factors for death of invasive Candida infections in critical care: a multicenter, prospective, observational study in France (2005-2006). Crit Care Med 2009; 37: $1612-8$.

35. Bougnoux ME, Kac G, Aegerter P, d'Enfert C, Fagon JY. Candidemia and candiduria in critically ill patients admitted to intensive care units in France: incidence, molecular diversity, management and outcome. Intensive Care Med 2008; 34: 292-9.

36. Wey SB, Mori M, Pfaller MA, Woolson RF, Wenzel RP. Risk factors for hospital-acquired candidemia. A matched case control study. Arch Intern Med 1989; 149: 2349-53.

37. Pfaller MA, Messer SA, Boyken L, Tendolkar S, Hollis RJ, Diekema DJ. Geographic variation in the susceptibilities of invasive isolates of Candida glabrata to seven systemically active antifungal agents: a global assessment from the ARTEMIS antifungal surveillance program conducted in 2001 and 2002. J Clin Microbiol 2004; 42: 3142-6.

38. Kuzucu Ç, Yetkin G, Çalişkan A. Bir yıl içerisinde kan kültürlerinden izole edilen candida türlerinin dağılımı ve antifungal duyarlılıkları. Erciyes Tip Dergisi (Erciyes Med J) 2007; 29: 115-9.

39. Yenişehirli G, Bulut Y, Günday E. Yoğun bakım ünitesinde yatan hastaların kan kültürlerinden izole edilen C. albicans sușlarında antifungal duyarlılık. ANKEM Derg 2007; 21: 146-9.

40. Mokaddas EM, Noura AZ, Khan U. Species distribution and antifungal susceptibility of Candida bloodstream isolates in Kuwait: a 10-year study. J Med Microbiol 2007; 56: 255-9.
41. Blumberg HM, Jarvis WR, Soucie JM, Edwards JE, Patterson JE, National Epidemiology of Mycoses Survey (NEMIS) Study Group et al. Risk factors for candidal bloodstream infections in surgical intensive care unit patients: the NEMIS prospective multicenter study. The National Epidemiology of Mycosis Survey. Clin Infect Dis 2001; 33: 177-86. Epub 2001 Jun 20

42. Guery BP, Arendrup MC, Auzinger G, Azoulay E, Borges Sá $\mathrm{M}$, Johnson EM et al. Management of invasive candidiasis and candidemia in adult non-neutropenic intensive care unit patients: Part i. Epidemiology and diagnosis. Intensive Care Med 2009; 35: 55-62.

43. Krogh-Madsen M, Arendrup MC, Heslet L, Knudsen JD. Amphotericin $\mathrm{B}$ and caspofungin resistance in Candida glabrata isolates recovered from a critically ill patient. Clin Infect Dis 2006; 42: 938-44.

44. Kiraz N, Oz Y. Species distribution and in vitro antifungal susceptibility of clinical Candida isolates from a university hospital in Turkey over a 5-year period. Medical Mycology 2011; 49: 126-31.

45. Diaz-Granados CA, Martínez A, Deaza C, Valderrama S. An outbreak of Candida spp. bloodstream infection in a tertiary care center in Bogotá, Colombia. Braz J Infect Dis 2008; 12: 390-4.

46. Morrell M, Fraser VJ, Kollef MH. Delaying the empiric treatment of candida bloodstream infection until positive blood culture results are obtained: a potential risk factor for hospital mortality. Antimicrob Agents Chemother 2005; 49: 3640-5.

47. Kumar A, Ellis P, Arabi Y, Roberts D, Light B, Parrillo JE et al. Initiation of inappropriate antimicrobial therapy results in a fivefold reduction of survival in human septic shock. Chest 2009; 136: 1237-48

48. Diekema DJ, Messer SA, Brueggemann AB, Coffman SL, Doern GV, Herwaldt LA et al. Epidemiology of candidemia: 3-year results from the emerging infections and the epidemiology of Iowa organisms study. J Clin Microbiol 2002; 40: 1298-1302.

49. Tritipwanit K, Chindamporn A, Suankratay C. Epidemiology of candidemia at King Chulalongkorn Memorial Hospital, Thailand. J Infect Dis Antimicrob Agent 2005; 22: 59-69.

50. Jutiamornlerd N, Chusri S, Siripaitoon P. Epidemiology of Candidemia in Songklanagarind Hospital. J Med Assoc Thai 2011; 94: 927-32.

51. Nucci M, Anaissie E, Betts RF, Dupont BF, Wu C, Buell DN et al. Early removal of central venous catheter in patients with candidemia does not improve outcome: analysis of 842 patients from 2 randomized clinical trials. Clin Infect Dis 2010; 51: 295-03.

52. Mermel LA, Allon M, Bouza E, Craven DE, Flynn P, O'Grady PO et al. Clinical practice guidelines for the diagnosis and management of intravascular catheter-related infection: 2009 update by the Infectious Diseases Society of America. Clin Infect Dis 2009; 49: 1-45. 